КОЛОНКА ГЛАВНОГО РЕДАКТОРА

DOI: https://doi.org/10.15688/lc.jvolsu.2020.2.1

UDC 343.3(470+571)

LBC 67.99(2Poc) 401.132

\title{
EXTREMISM AS A THREAT TO NATIONAL SECURITY: YESTERDAY, TODAY, AND TOMORROW
}

\author{
Agnessa O. Inshakova \\ Volgograd State University, Volgograd, Russian Federation
}

\begin{abstract}
Annotation. The editor-in-chief paper is devoted to one of the most serious problems of Russia's national security, extremist activities, which poses a real threat to the life of the state, encroaches on the constitutional rights and freedoms of Russian citizens, sovereign democracy and public order. It is noted that for the Russian Federation, as a multinational state, extremism is a particular danger, since it undermines the peaceful coexistence of various ethnic and social groups. When describing the relevance of the problem, the paper takes into account the features and relationship of extremism with the predicted negative consequences in the context of globalization of the world economic relations and information and technological development of society in the era of neoindustrialization. The author questions the stereotype that exists in the public consciousness, according to which the extremist organizations, movements, the propaganda of radical views and crimes of an extremist nature are, to a greater extent, already a historical phenomenon, which are characteristic, first of all, of the 90-ies of the XX century. It is argued that the problem under consideration "mutates" and takes on new guises in the conditions of modern reality. It is established that the new legal tools and mechanisms developed over the years are being added as a result of scientific and technological progress. Thus, in the conditions of the sixth technological paradigm, there appear new varieties of extremism, for example, cyberextremism. At the same time, cybersecurity serves as a binding condition for the successful development and operation of industry 4.0 technologies. Based on the results of a comprehensive analysis of the research conducted by the author, as well as taking into account the opinions of the scientists expressed in the main topic of the issue, it is concluded that in the era of the deepening processes of digital interdependence, the international organizations, both intergovernmental and non-governmental, as well as the scientists and practitioners dealing with the security issues should accumulate their efforts to expand digital cooperation in order to protect human rights and eliminate the threats of cyberextremism. The shared human values such as equality, privacy, dignity, freedom, inclusiveness, respect and sustainability should serve as a beacon for legal scholars in the digital age. Modern technologies bring great benefits to all mankind. Moreover, they help protect human rights, but these same technologies can and are already being used to infringe on human rights by both the states and the private sector.

Key words: extremism, extremist organizations, globalization, neoindustrialization, the sixth technological order, cyberextremism, cybersecurity, prevention and counteraction of extremism, crimes of extremist orientation, national security, social and legal methods of combating extremism.
\end{abstract}

तิ Citation. Inshakova A.O. Extremism as a Threat to National Security: Yesterday, Today, and Tomorrow. Legal Concept, 2020, vol. 19, no. 2, pp. 6-12. (in Russian). DOI: https://doi.org/10.15688/lc.jvolsu.2020.2.1 
УДК 343.3(470+571)

ББК 67.99(2Рoc)401.132

\title{
ЭКСТРЕМИЗМ КАК УГРОЗА НАЦИОНАЛЬНОЙ БЕЗОПАСНОСТИ: ВЧЕРА, СЕГОДНЯ, ЗАВТРА
}

\section{Агнесса Олеговна Иншакова}

\author{
Волгоградский государственный университет, г. Волгоград, Российская Федерация
}

\begin{abstract}
Аннотация. Статья главного редактора посвящена одной из серьезнейших проблем национальной безопасности РФ - экстремистской деятельности, которая создает реальную угрозу жизнедеятельности государства, посягает на конституционные права и свободы российских граждан, суверенную демократию и общественный порядок. Отмечается, что для РФ как многонационального государства экстремизм представляет особую опасность, поскольку подрывает мирное сосуществование различных этнических и социальных групп. При описании актуальности проблемы в статье учитываются особенности и взаимосвязь экстремизма с прогнозируемыми негативными последствиями в условиях глобализации мировых хозяйственных связей и информационно-технологического развития общества в эпоху неоиндустриализации. Автор ставит под сомнение бытующий в общественном сознании стереотип, согласно которому экстремистские организации, движения, пропаганда радикальных взглядов и преступлений экстремистского характера являются в большей степени уже историческим явлением, характерным, прежде всего, для 90-х гг. ХХ века. Утверждается, что рассматриваемая проблема «мутирует» и принимает новые обличия в условиях современной действительности. Установлено, что к разработанным за эти годы правовым средствам и механизмам добавляются новые вследствие научно-технического прогресса. Так, в условиях шестого технологического уклада появляются новые разновидности экстремизма, например, киберэкстремизм. Вместе с тем кибербезопасность служит обязательным условием для успешного внедрения и функционирования технологий индустрии 4.0. По результатам комплексного анализа исследования, проведенного автором, а также с учетом мнений ученых, высказанных в главной теме номера, делается вывод о том, что в эпоху углубляющихся процессов цифровой взаимозависимости, международные организации (как межправительственные, так и неправительственные), а также ученые и практики, занимающиеся проблемами безопасности, должны аккумулировать свои усилия, чтобы расширять цифровое сотрудничество с целью защиты прав человека и нивелирования угроз киберэкстремизма. Общие человеческие ценности, такие как равенство, неприкосновенность частной жизни, достоинство, свобода, инклюзивность, уважение и устойчивость, должны служить маяком для правоведов в эпоху цифровых технологий. Современные технологии приносят огромную пользу всему человечеству. Более того, они помогают защищать права человека, но эти же технологии могут использоваться и уже используются для ущемления прав человека как государствами, так и частным сектором.

Ключевые слова: экстремизм, экстремистские организации, глобализация, неоиндустриализация, шестой технологический уклад, киберэкстремизм, кибербезопасность, профилактика и противодействие экстремизму, преступления экстремистской направленности, национальная безопасность, социально-правовые методы борьбы с экстремизмом.
\end{abstract}

Цитирование. Иншакова А. О. Экстремизм как угроза национальной безопасности: вчера, сегодня, завтра // Legal Concept = Правовая парадигма. - 2020. - Т. 19, № 2. - C. 6-12. - DOI: https://doi.org/10.15688/ lc.jvolsu.2020.2.1

Главная тема очередного номера юридического журнала Волгоградского государственного университета «Legal Concept $=$ Правовая парадигма» - экстремизм как социально-правовое явление в современной России, представляющее одну из серьезнейших угроз национальной безопасности РФ. Экстремистская деятельность создает реальную угрозу жизнедеятельности государства, посягает на конституционные права и свободы российских граждан, общественную безопасность и общественный порядок. Для РФ как многонационального государства экстремизм представляет особую опасность, поскольку подрывает мирное сосуществование различных этнических и социальных групп.

В связи с глобализационными процессами экстремизм приобретает значительные масштабы и проявляется в различных сфеpax жизнедеятельности. Несмотря на то что 
в общественном сознании существует стереотип, согласно которому экстремистские организации, движения, пропаганда радикальных взглядов и преступлений экстремистского характера являются в большей степени уже историческим явлением, характерным, прежде всего, для 90-х гг. ХХ в., данная проблема не перестает быть актуальной и сегодня. К разработанным за эти годы правовым средствам и механизмам добавляются новые вследствие научно-технического прогресса и четвертой промышленной революции.

В условиях шестого технологического уклада появляются новые разновидности экстремизма, например, киберэкстремизм. Одновременно с этим кибербезопасность служит обязательным условием для успешного внедрения и функционирования технологий индустрии 4.0. В частности, становится очевидно, что расширение сферы использования роботизированных устройств в различных сферах общественной жизни порождает необходимость анализа содержания правового режима робота и его соотношения с правовым статусом субъектов права. Интернет вещей, который сегодня внедрен во многие сферы жизнедеятельности, в том числе в промышленность, обусловливает потребность в формировании превентивно-профилактических средств защиты как субъектов хозяйствования, так и потребителей. Облачные вычисления, интеграция IT-систем, дополненная реальность сегодня рассматриваются как перспективные средства оптимизации предпринимательской деятельности, внедрение которых также должно иметь научно обоснованные подходы, в том числе с целью правового обеспечения вопросов кибербезопасности.

По результатам проведенного автором анализа [1], а также с учетом мнений ученых, высказанных в главной теме номера, можно заключить, что в эпоху углубляющихся процессов цифровой взаимозависимости международные организации (как межправительственные, так и неправительственные), а также ученые и практики, занимающиеся проблемами безопасности, должны аккумулировать свои усилия, чтобы расширять цифровое сотрудничество с целью защиты прав человека и нивелирования угроз киберэкстремизма. Общие человеческие ценности, такие как ра- венство, неприкосновенность частной жизни, достоинство, свобода, инклюзивность, уважение и устойчивость, должны быть сохранены. Эти человеческие ценности должны служить маяком для правоведов в эпоху цифровых технологий. Международное право по своей природе действует на принципах демократии, которая является целью государств в эпоху цифровых технологий. Современные технологии приносят огромную пользу всему человечеству. Более того, они помогают защищать права человека, но эти же технологии могут использоваться и уже используются для ущемления прав человека как государствами, так и частным сектором.

К сожалению, подготовленный номер не затронул проблем правового регулирования борьбы с киберэкстремизмом и в основном представлен лишь работами уголовно-правового характера, содержащими результаты, направленными на борьбу с традиционными проявлениями экстремисткой деятельности. При этом, следуя общенаучному исследовательскому подходу и двигаясь от общего к частному, члены редакционной коллегии журнала приняли решение посвятить в ближайшем времени отдельный номер журнала «Legal Concept $=$ Правовая парадигма» проблемам правового обеспечения кибербезопасности.

Что же касается проблем, обсуждаемых на страницах этого журнала, то авторами установлено, что в российском социуме имеется целый ряд неблагоприятных общественных факторов, склоняющих граждан к осуществлению экстремистской деятельности. К ним, прежде всего, следует отнести: чрезмерную поляризацию высших и низших социальных групп; когнитивный диссонанс; социально-экономические проблемы, детерминирующие снижение востребованности креативного потенциала граждан; идеологический прессинг со стороны радикальных общественных организаций и т. д. В связи с этим возрастает необходимость в организации эффективного противодействия экстремизму, совершенствования деятельности правоохранительных органов при осуществлении борьбы с этим негативным феноменом. Профилактика и противодействие экстремизму является комплексной проблемой, в связи с чем важным в ее решении видится участие институтов граж- 
данского общества. Это отметил и Президент РФ В.В. Путин в феврале 2020 г., выступая на коллегии ФСБ: «Более гибкой и современной должна стать система противодействия экстремизму. Важно опираться здесь на поддержку и доверие общества». Так, глобальные вызовы российскому социуму и сложности догоняющей модернизации обусловливают необходимость постоянного повышения качества работы силовых структур и гражданского общества по предупреждению и пресечению актов экстремистской деятельности.

Таким образом, актуальность проблемы в контексте научного дискурса определяется:

- во-первых, возросшими рисками, вызванными развитием целого ряда негативных явлений (экстремизма, религиозного радикализма, правового нигилизма, ксенофобии и пр.) в общественной жизни российских граждан;

- во-вторых, концептуальным осмыслением проблемы институционализации взаимодействия государства гражданского общества в контексте решения задач по профилактике экстремизма;

- в-третьих, научным обоснованием внедрения в правоприменительную практику рекомендаций по повышению эффективности противодействия экстремизму;

- в-четвертых, углублением теоретического анализа проблем оптимального использования ресурсов для борьбы с экстремизмом.

Статьи, опубликованные в рубрике «Главная тема номера», содержат в себе правовые проблемы и пути их решения как теоретического, так и прикладного характера. Авторами представленных научных работ выступили российские ученые в области уголовного процесса, криминалистики, теории и истории права и государства, политологии, социологии, а также практические работники (сотрудники полиции, помощник прокурора, мировой судья и судебный медик). Две из девяти статей («Расследование преступлений экстремистской направленности» и «Интеграция деятельности государства и гражданского общества по профилактике молодежного экстремизма в контексте правовой социализации») подготовлены при финансовой поддержке Российского фонда фундаментальных исследований (проект № 20-011-00688 (А) «Модель профилактики экстремизма в моло- дежной среде: интеграция деятельности гражданских ассоциаций и силовых структур в контексте правовой социализации»).

Несомненный научный интерес представляет статья «Расследование преступлений экстремистской направленности», подготовленная доктором юридических наук, профессором, профессором кафедры уголовного процесса Саратовской государственной юридической академии Ю.В. Францифоровым и кандидатом юридических наук, доцентом, директором института права Волгоградского государственного университета В.М. Шинкаруком. Работа посвящена разработке концептуальных рекомендаций по повышению результативности расследования преступлений экстремистской направленности, реализации мер по ужесточению уголовно-правовой политики, активизации международного и внутригосударственного сотрудничества субъектов расследования, направленных на предупреждение и дальнейшую минимизацию последствий экстремизма. В процессе научного взаимодействия ученым удалось определить меры повышения эффективности расследования преступлений экстремистской направленности.

Междисциплинарный подход к решению проблемы профилактики экстремизма в молодежной среде прослеживается в научной статье «Интеграция деятельности государства и гражданского общества по профилактике молодежного экстремизма в контексте правовой социализации», подготовленной молодым кандидатом политических наук П.П. Фантровым и кандидатом юридических наук, доцентом, заведующей кафедрой уголовного процесса и криминалистики Волгоградского государственного университета Н.А. Соловьевой. В результате проведенного исследования ученые приходят к выводу, что эффективность борьбы с проявлениями экстремизма в молодежной среде и успешность правовой социализации молодых граждан зависят, прежде всего, от системной работы государства и гражданского общества, что объективно требует реализации определенных технологий в качестве посильных помощников, например, сетевого краудсорсинга. Широкое внедрение последнего в жизнедеятельность российского общества, по мнению ав- 
торов, способно «социализировать» систему профилактики молодежного экстремизма, однако при условии, что в качестве ее акторов выступают не только государственные структуры, но и конструктивно настроенные ассоциации граждан.

Кандидатом юридических наук, доцентом, доцентом кафедры уголовного процесса и криминалистики Волгоградского государственного университета С.Ю. Бирюковым в соавторстве с доктором юридических наук, профессором, профессором кафедры исследования документов Московского университета МВД РФ М.В. Бобовкиным, а также доктором юридических наук, профессором, профессором кафедры уголовного процесса Волгоградской академии МВД России М.А. Шматовым в статье «Общая характеристика экстремизма и анализ современного состояния борьбы с преступлениями экстремистской направленности» представлен анализ мер по борьбе с преступлениями экстремистского характера в современной России.

Статья кандидата юридических наук, доцента, доцента кафедры криминалистики Саратовской государственной юридической академии О.А. Славгородской на тему «Реализация воспитательной функции допроса свидетеля как элемента противодействия преступлениям экстремистской направленности» также носит междисциплинарный характер. Проблемы, затронутые в ее работе, весьма актуальны в связи с необходимостью формирования нравственно ориентированной личности для совершенствования мер по противодействию экстремизму. О.А. Славгородская выявила взаимосвязь между воспитательным воздействием, оказываемым следователем при производстве допросов свидетелей при расследовании преступлений экстремистской направленности, и обосновала тезис о том, что воспитательное воздействие может использоваться в качестве одной из мер по противодействию преступлений данного вида.

В статье кандидата юридических наук, доцента, доцента кафедры уголовного процесса и криминалистики Саратовской государственной юридической академии М.А. Барановой под названием «Проблемные вопросы определения территориальной подследственности уголовных дел о преступлениях экстремистской направлен- ности» рассмотрены существующие теоретические конструкции определения места совершения преступления экстремистской направленности с применением информационно-телекоммуникационных сетей и, соответственно, территориальной подследственности уголовных дел. Автор исследования справедливо отмечает, что для правильного определения подследственности уголовных дел экстремистской направленности следует руководствоваться действующими положениями частей 3,4 и 4.1 статьи 152 УПК РФ, не дожидаясь разработки единого международного акта.

Пониманию реального состояния прокурорского надзора за исполнением законов о противодействии экстремизму среди трудовых мигрантов служит научная публикация «Координационная деятельность органов прокуратуры по противодействию и профилактике экстремизма среди трудовых мигрантов в современной России», подготовленная старшим преподавателем кафедры уголовного процесса и криминалистики Волгоградского государственного университета Д.Г. Каххоровым, доктором юридических наук, профессором кафедры теории и истории права и государства Волгоградского государственного университета В.М. Абдрашитовым и помощником прокурора города Канибадам Республики Таджикистан Ш.Х. Мачидзодой. Исследовательским коллективом авторов предложены рекомендации по совершенствованию форм координационной деятельности органов прокуратуры по предупреждению и пресечению актов экстремисткой деятельности.

Методологический характер носит статья «Методика оперативно-розыскного противодействия преступлениям экстремистской направленности оперативными подразделениями органов внутренних дел», подготовленная доктором юридических наук, профессором, профессором кафедры уголовного процесса, криминалистики и правовой информатики Балтийского федерального университета им. И. Канта Е.Н. Холоповой и адъюнктом кафедры оперативно-розыскной деятельности в органах внутренних дел Санкт-Петербургского университета Министерства внутренних дел Российской Федерации Ю.О. Копченковой. Результатом проведенного ими исследования является разработка методики оперативно-розыскного 
противодействия преступлениям экстремистской направленности оперативными подразделениями органов внутренних дел, состоящей из комплекса ситуационно ориентированных рекомендаций, имеющих практическую значимость при выявлении, предупреждении и раскрытии экстремистских преступлений.

Особую практическую ценность представляет статья «Особенности профилактики экстремизма в молодежной среде», выполненная коллективом авторов, которые имеют опыт работы в правоохранительных органах более 15 лет: полковник полиции в отставке, кандидат юридических наук, доцент, доцент кафедры уголовного процесса и криминалистики Волгоградского государственного университета П.П. Мураев; начальник ОУУП и ПДН Управления МВД России по городу Волгограду Д.Н. Яковлев; старший инспектор ОУУП и ПДН Управления МВД России по городу Волгограду В.В. Шалимова. В представленной работе авторы охарактеризовали проблемы молодежного экстремизма и выявили перспективные направления его профилактики с помощью методов правовой статистики, показали результаты борьбы с молодежным экстремизмом в г. Волгограде, установленные эмпирическим путем, а также разработали практическиерекомендации органам полиции по повышению эффективности профилактики данного феномена на региональном уровне.

Криминалистические и судебно-медицинские аспекты экстремизма как социально-правового явления рассмотрены в статье «Осмотр трупа, обнаруженного на месте взрыва», подготовленной кандидатом медицинских наук, доцентом, заведующим отделением судебномедицинской экспертизы (г. Волгоград) филиала № 2 ФГКУ «111 Главный государственный центр судебно-медицинских и криминалистических экспертиз» Министерства обороны Российской Федерации А.А. Меденцовым и кандидатом юридических наук, доцентом, доцентом кафедры уголовного процесса и криминалистики Волгоградского государственного университета Е.С. Азаровой. Авторами статьи охарактеризованы современные принципы тактики проведения осмотра места происшествия, уточнены требования и рассмотрены особенности оформления протокола осмотра места происшествия при взрывах, разработаны реко- мендации концептуального характера по исследованию и изъятию объектов.

Судебно-психологический аспект темы главной рубрики журнала затронут в статье кандидата социологических наук, доцента, доцента кафедры уголовного процесса и криминалистики Волгоградского государственного университета О.Е. Андрющенко и мирового судьи судебного участка № 47 Волгоградской области, кандидата юридических наук, доцента кафедры уголовного процесса и криминалистики Волгоградского государственного университета В.Н. Перекрестова под названием «Установление достоверности показаний несовершеннолетних в ходепроизводства судебно-психологической экспертизы по уголовным делам о преступлениях экстремистской направленности». В контексте рассматриваемой проблематики исследователи выделяют три концептуальных подхода: 1) невозможность использования детских показаний по уголовным делам о преступлениях экстремистской направленности, поскольку они не представляют доказательной ценности; 2) необходимость строгого ранжирования показаний несовершеннолетних лиц по возрастным признакам; 3) допрос несовершеннолетних по уголовным делам о преступлениях экстремистской направленности следует рассматривать как процессуальное действие.

Разнообразие разработанных авторами вопросов как нельзя лучше показало многоаспектность заявленной темы, несмотря на превалирование уголовно-правовой и уголовно-процессуальной сфер в комплексе представленных в главной теме номера правовых изысканий. Редакционная коллегия журнала надеется, что собранные в вышеуказанной рубрике статьи не только дадут новый импульс теоретическому развитию социальноправового познания, но и будут полезными для совершенствования правоприменительной практики в сфере борьбы с экстремизмом.

\section{СПИСОК ЛИТЕРАТУРЫ}

1. Competitive Russia: Foresight Model of Economic and Legal Developmentint he Digital Age: Proceedings of the International Scientific Conferencein Memory of Oleg Inshakov (1952-2018) / ed. by A. O. Inshakova, E. I. Inshakova. - Cham : Springer Nature, 2020. - [In print]. 
КОЛОНКА ГЛАВНОГО РЕДАКТОРА

\section{REFERENCES}

1. Competitive Russia: Foresight Model of Economic and Legal Developmentint he Digital Age:
Proceedings of the International Scientific Conferencein Memory of Oleg Inshakov (1952-2018). Ed. by A.O. Inshakova, E.I. Inshakova. Cham, Springer Nature, 2020. [In print].

\section{Information About the Author}

Agnessa O. Inshakova, Doctor of Sciences (Jurisprudence), Professor, Head of the Department of Civil and International Private Law, Base Department of the Southern Scientific Centre of the Russian Academy of Sciences, Volgograd State University, Prosp. Universitetsky, 100, 400062 Volgograd, Russian Federation, gimchp@volsu.ru, https://orcid.org/0000-0001-8255-8160

\section{Информация об авторе}

Агнесса Олеговна Иншакова, доктор юридических наук, профессор, заведующая кафедрой гражданского и международного частного права (базовая кафедра ЮНЦ РАН), Волгоградский государственный университет, просп. Университетский, 100, 400062 г. Волгоград, Российская Федерация, gimchp@volsu.ru, https://orcid.org/0000-0001-8255-8160 